\title{
A supervisão como ferramenta gerencial para a produção do cuidado em UTI: uma reflexão do agir do enfermeiro
}

\author{
André Henrique do Vale de Almeida*, Magno Conceição das Merces**, Maria Lúcia Silva Servo, D.Sc.***
}

*Enfermeiro, Especialista em Unidade de Terapia Intensiva Adulto, Mestrando em Saúde Coletiva pela Universidade Estadual de Feira de Santana (UEFS), **Biólogo Sanitarista, Enfermeiro, Especialista em Gestäo Hospitalar, Mestrando em Saúde Coletiva pela UEFS, Professor Auxiliar da Universidade do Estado da Bahia (UNEB), ${ }^{* * *}$ Enfermeira, Professora Plena da UEFS

\section{Resumo}

Este estudo tem como objetivo analisar a supervisão como ferramenta gerencial do enfermeiro para a produção do cuidado em UTI segundo a literatura brasileira do período de 2001-2011. Foi realizada a leitura vertical e horizontal do material obtido, de forma minuciosa, buscando identificar as informaçóes mais relevantes. Diante dos objetivos propostos e da análise dos dados, o estudo apontou as categorias a seguir: a supervisão como ferramenta gerencial do enfermeiro para a produção do cuidado em UTI e os limites e as possibilidades para a supervisão como ferramenta gerencial do enfermeiro para a produção do cuidado em UTI. Observou-se através dos resultados que a supervisão atual perpassa pelos sentimentos que estão aflorados na UTI, seja em relação aos pacientes, como também a todos os membros da equipe, além do aprimoramento dos trabalhadores, estimulando o exercício de suas habilidades e competências individuais.

Palavras-chave: supervisão, Unidade de Terapia Intensiva, Enfermagem.

\section{Abstract \\ Supervision as a management tool for production of care in ICU: nurses thinking on action based on literature}

This study aims at analyzing the supervision as a nurse management tool for the production of care in the ICU according to the Brazilian literature published in the period 2001-2011. We performed vertical and horizontal reading of the material obtained, in detail, identifying the most relevant information. Considering the purpose of this study and the data analysis, the study identified the following categories: the supervision as a nurse management tool for production of care in ICU and the limits and possibilities for the supervision as a nurse management tool for the production of care in ICU. The results showed that the current supervision pervades the feelings that are emerged in the ICU, either in relation to patients, as well as in relation to all team members, besides the improvement of workers, encouraging the exercise of their abilities and skills.

Key-words: supervision, Intensive Care Unit, Nursing. 


\section{Resumen}

\section{Supervisión como herramienta de gestión para la producción de cuidados en UCl: una reflexión del actuar del enfermero a partir de la literatura}

Este estudio tiene como objetivo analizar la supervisión del enfermero como herramienta de gestión para la producción de cuidados en UCI de acuerdo a la literatura brasileńa del período 2001-2011. Se llevó a cabo la lectura vertical y horizontal del material obtenido, en detalle, con el fin de identificar las informaciones más relevantes. Teniendo en cuenta los objetivos propuestos y el análisis de los datos, el estudio identificó las siguientes categorías: supervisión de la enfermera como herramienta de gestión para la producción de cuidados en UCI y los límites y posibilidades de la supervisión como herramienta de gestión del enfermero para la producción de cuidados en UCI. Los resultados muestran que la supervisión actual trasciende los sentimientos que afloran en la UCI, sea en relación a los pacientes, sino también a todos los miembros del equipo, así como la mejora de los trabajadores, estimulando el ejercicio de sus habilidades y capacidades individuales.

Palabras-clave: supervisión, Unidad de Cuidados Intensivos, Enfermería.

\section{Introdução}

Ao se tratar de cuidado na Unidade de Terapia Intensiva (UTI), é fundamental salientar que as profissóes da saúde utilizam de seu conhecimento do mundo e de seu conhecimento específico para prestar esse cuidado. Os enfermeiros utilizam-se do diálogo, da relação interpessoal, das técnicas e procedimentos [1]. O desenvolvimento do saber da enfermagem faz-se através da reflexão acerca das açóes cotidianas e principalmente pela vontade de avançar, acrescentando, ao fazer tecnicista, um pensar e agir mais humanitário [2].

Em decorrência da complexidade do avanço tecnológico, do conhecimento biomédico e da qualificação do cuidado, foram criadas as UTI, onde existem maiores condiçóes para estabilizar o paciente e promover sua recuperação. Entretanto, a UTI se transformou em um ambiente onde a técnica se sobrepóe ao cuidado, e os profissionais estão demasiadamente envolvidos com máquinas e monitores, esquecendo que existem pessoas envolvidas no processo do cuidado [3].

O cuidado é tudo aquilo que se aglutina sob a forma de açóes ou intervençóes, que contribuem para gerar, organizar ou (re)estabelecer esperança, autonomia, a liberdade de escolha, as relaçóes humanas e o sentido da vida [4]. Nas Unidades de Produçáo do Cuidado, onde são processados os encontros entre usuários e trabalhadores, é possível observar fenômenos menos relacionados ao cognoscitivo e mais atrelados ao campo dos agenciamentos de subjetividade [5].

Ao longo dos anos a supervisão sofreu modificaçôes, deixando de ter um caráter fiscalizador e punitivo, passando a acompanhar, qualificar e gerenciar os recursos humanos e materiais. Contudo, para que isso ocorra, faz-se necessário um planejamento adequado, recursos materiais disponíveis, profissionais bem remunerados e qualificados, e um supervisor que valorize o trabalho desempenhado pela sua equipe [6].

Atualmente, a enfermagem executa ações de gerência de unidade através da previsão, provisão, manutenção e controle de recursos humanos e materiais para o bom funcionamento do serviço, como também é responsável pelo cuidado aos pacientes realizado pelo diagnóstico, planejamento, execução e avaliação da assistência, abarcando a delegação de atividades, a orientação e supervisão da equipe de enfermagem [7].

Supervisionar envolve uma diversidade de açóes, que requerem do enfermeiro conhecimento científico, habilidade para gerir e motivar pessoas, além de sabedoria e paciência para trabalhar com as diferenças. Outrossim, é necessário que o enfermeiro entenda que ele não gerencia sozinho e sem adversários, e apreenda que a realidade é dinâmica e que certas açóes aumentarão o apoio, enquanto outras podem criar resistências [8].

Através da supervisão é possível manter a educação permanente da equipe de enfermagem com a constante avaliaçáo do serviço, identificando as necessidades de orientação e treinamento com o objetivo de prevenir problemas [9].

Não basta ao enfermeiro dominar o saber técnico para supervisionar, é mister o entendimento das pessoas e dos grupos, da importância das relaçóes de trabalho dentro da equipe para que a supervisão 
seja uma ferramenta qualificadora da prática de enfermagem [10]. Compreender a supervisão envolve a percepção da posição ocupada dentro da equipe, e o relacionamento com os demais membros respeitando as individualidades, emoçóes e a hierarquia. Liderar é um ato complexo e desafiador, que requer do enfermeiro, acima de tudo, capacidade de se relacionar [6].

Justificamos esta pesquisa pela importância da supervisão na produção do cuidado em UTI e pelo papel que o enfermeiro exerce nesse processo - $\mathrm{o}$ gerenciamento de recursos materiais, a supervisão e a assistência direta ao paciente -, e pela dificuldade encontrada em obter conhecimento sobre o assunto, visto que a supervisão como ferramenta gerencial na produçáo do cuidado da enfermagem é uma prática pouco explorada.

Desse modo questionamos: Como a supervisão se constitui em ferramenta gerencial do enfermeiro de UTI para a produçáo do cuidado segundo a literatura brasileira do período de 2001-2011?

Estimamos que este artigo contribua para aclarar as nuances que envolvem a supervisão aplicada à produção do cuidado em enfermagem na UTI, tendo em vista a necessidade dos enfermeiros no exercício dessa função.

Este estudo tem como objetivo geral analisar a supervisão como ferramenta gerencial do enfermeiro para a produçáo do cuidado em UTI segundo a literatura brasileira do período de 2001-2011, e como objetivo específico, apontar os limites e as possibilidades para a supervisão como ferramenta gerencial do enfermeiro para a produção do cuidado em UTI.

\section{Material e métodos}

Trata-se de um artigo de revisão de literatura de abordagem qualitativa, exploratória, em artigos publicados no período de 2001-2011 na Revista Brasileira de Enfermagem e na Revista Gaúcha de Enfermagem, referentes ao gerenciamento em enfermagem, em serviços de internação hospitalar, particularmente na Unidade de Terapia Intensiva.

Os critérios de inclusão das publicações foram os estudos em português em periódicos nacionais escritos por enfermeiros que abordavam os aspectos relacionados à supervisão do enfermeiro e a produção do cuidado em UTI.

Foi realizada a leitura vertical e horizontal do material obtido, de forma minuciosa, buscando identificar as informaçóes mais relevantes. As informaçóes foram organizadas tendo como referência a proposta da análise de conteúdo, que, segundo Bardin, ocorre nas etapas de pré-análise, exploração do material e tratamento dos resultados [11].

Os resultados foram apresentados a partir das categorias: a supervisão como ferramenta gerencial do enfermeiro para a produção do cuidado em UTI, e os limites e as possibilidades para a supervisão como ferramenta gerencial do enfermeiro para a produçáo do cuidado em UTI, relacionadas com a fundamentação teórica.

\section{Resultados e discussão}

O estudo apontou a partir dos objetivos propostos e da análise dos dados as seguintes categorias: a supervisão como ferramenta gerencial do enfermeiro para a produção do cuidado em UTI e os limites e as possibilidades para a supervisáo como ferramenta gerencial do enfermeiro para a produção do cuidado em UTI.

\section{A supervisão como ferramenta gerencial do en- fermeiro para a produçáo do cuidado em UTI}

A supervisão emerge da necessidade de observação das atividades desempenhadas, bem como da avaliação das técnicas e saberes orientados, funcionando como importante ferramenta para gerir e organizar o trabalho em saúde, possibilitando intervençóes mais bem planejadas e executadas.

$\mathrm{Na}$ enfermagem atual, a gerência de unidade consiste na previsão, provisão, manutenção, controle de recursos materiais e humanos para o funcionamento do serviço, e gerência do cuidado que consiste no diagnóstico, planejamento, execução e avaliação da assistência, passando pela delegação das atividades, supervisão e orientação da equipe [7].

$\mathrm{O}$ enfermeiro deve apreender o administrar como parte integrante do processo do cuidado, e que ao planejar, executar e avaliar suas açóes cotidianas ele está contribuindo para um cuidar mais humanizado, resolutivo e integral.

Corroboramos com Correia e Servo, quando mencionam que "o enfermeiro faz parte da equipe de enfermagem e na medida em que avalia o serviço no qual está inserido, realiza sua auto avaliação, pois a efetividade do serviço esta diretamente relacionada a sua atuaçáo enquanto supervisor" [12]. 
A realidade vivenciada pelo enfermeiro intensivista está permeada tanto de atividades assistenciais quanto de gerência. Através de sua supervisão, o enfermeiro contribui para a eficiência do trabalho, e para a eficácia dos métodos e técnicas empregados, objetivando uma maior resolutividade na assistência.

Greco analisa que na prática, "enquanto enfermeiros desempenhando a função gerencial, as gerências da unidade e do cuidado estáo associadas, uma vez que o enfermeiro ao gerenciar recursos em geral deve estar voltado para o processo assistencial e não pode perder de vista a qualidade da assistência" [7].

O exercício da supervisão em enfermagem requer do profissional diversas habilidades, visto que engloba a assistência direta ao usuário, a capacidade de dialogar com os demais profissionais de saúde, orientação da equipe de enfermagem, agir politicamente, dentre outras açóes, como controle, educação, e avaliação.

Liberali e Dall'agnol abordam que o papel do supervisor passa a ser de um orientador e facilitador à medida que agrega esforços junto à equipe de enfermagem para solucionar as necessidades coletivas e individuais, buscando mecanismos resolutivos para as situaçóes rotineiras [13].

Neste sentido, Servo assinala que a supervisão em enfermagem "gera conflitos nas relaçóes que são permeadas por questóes técnicas e políticas, de relacionamento interpessoal, condiçóes de trabalho, e, sobretudo por embates relativos ao exercício da hierarquia e do poder, conforme a organizaçáo tecnológica e social do trabalho" [8].

Faz-se necessário que os enfermeiros supervisores busquem a todo o momento orientar e capacitar sua equipe, proporcionando um ambiente participativo, reflexivo e crítico, visando à melhoria na qualidade do atendimento. É fundamental uma liderança supervisora mais democrática, que só será alcançada quando o valor e a contribuição de cada ator social forem reconhecidos.

Concordamos com Correia e Servo quando afirmam que um dos objetivos da supervisão é manter a educação permanente dos trabalhadores de saúde através da constante avaliação do serviço, buscando identificar as necessidades de orientação e treinamento, no intuito de prevenir situaçóes problemáticas [12]. Nesse âmbito, o planejamento, a execução e a avaliação, são etapas do processo cíclico que constitui a metodologia da supervisão.

A mais importante ideia, integrante do planejamento normativo, é que se parte de uma visão unívoca da realidade que determina todos os momentos seguintes do planejamento. $\mathrm{O}$ paradigma que norteia as propostas gerenciais participativas náo são compatíveis com a proposta do planejamento normativo, visto que na gestão participativa a possibilidade de relaçóes igualitárias permite a complementariedade das potencialidades dos participantes, existindo distribuição de poderes, autonomia e responsabilidades [14].

Servo afirma que "a possibilidade de reflexão coletiva se faz presente visando a uma intervenção de enfermagem efetiva, sem perder de vista as especificidades inerentes às estruturas sociais concretas e à dinâmica das relaçóes sociais experienciadas pelos atores sociais em uma dada realidade" [8].

A assistência é só o início das atividades do enfermeiro que tem a função de organizar e planejar o trabalho a ser desenvolvido, durante o seu turno e muitas vezes do turno do colega. Gerenciar a assistência compreende interligá-la aos fins da enfermagem, utilizá-la como instrumento capaz de auxiliar no desenvolvimento da enfermagem e no planejamento de suas tarefas [15].

A supervisão de enfermagem na UTI assume um caráter particular, tratando-se de um setor onde o profissional se depara com pacientes em estado crítico e com risco iminente de morte. Neste cenário, há que se vislumbrar a integralidade, o vínculo e a responsabilizaçáo no cuidado ao paciente, buscando atender as necessidades singulares dos sujeitos.

Marques e Lima analisam que "na realidade dos serviços de saúde, o que se tem visto é a produção de atos na forma de procedimentos e da produção de procedimentos na forma de cuidado, sem haver compromisso com a cura/autonomia dos indivíduos" [16].

O gerenciamento do cuidado não vem sendo realizado pelos enfermeiros e não é cobrado pelas organizaçóes, que dão maior importância ao gerenciamento das unidades de trabalho. Contudo, ao preparar a equipe para oferecer um cuidado de qualidade, realizar auditorias para alimentar as açóes educativas e a revisáo dos processos, promovendo a qualidade do cuidado oferecido ao cliente, o enfermeiro estará exercendo uma forma bastante atual de gerenciar o cuidado [7].

Assumir o cuidado significa ter responsabilidade de articular os diferentes profissionais, em um trabalho em equipe, horizontal, visando o sujeito do cuidado em sua integralidade bio-psico-social-espiritual, com necessidades a serem atendidas, mas 
também com desejos, emoçóes, com objetividade e subjetividade [17].

Lucena e Crossetti, corroborando esse pensamento, afirmam que o cuidar voltado para a singularidade do Ser Humano, deixado muitas vezes em segundo plano em razáo de uma prática de cuidar mecanicista, sinaliza para a importância dos profissionais de saúde de terem a compreensão de que o seu existir não é distinto do existir daqueles que cuidam [18].

É inegável que os avanços tecnológicos das últimas décadas têm causado impacto positivo na saúde dos pacientes. Na UTI isso se torna ainda mais evidente, à medida que é o setor do hospital onde se encontra o maior aparato técnico, com máquinas sofisticadas e inovadoras, que contribuem para uma maior resolutividade da assistência ao paciente crítico.

A complexidade do cuidar na terapia intensiva, em razáo da continua evoluçáo dos recursos utilizados para o cuidado e tratamento dos pacientes, exige dos profissionais que ali atuam atenção no desempenho técnico e científico, além da percepção das necessidades individuais de cada paciente [18].

Para Martins et al., no trabalho desempenhado pelo enfermeiro "deve-se compreender que, além do cuidado dos indivíduos hospitalizados, é fundamental que sejam atendidas as necessidades destes, quer sejam elas biológicas, físicas, psíquicas ou espirituais" [15].

As tecnologias não são passíveis de hierarquização pela importância ou complexidade, elas podem ser consumidas conforme as necessidades de cada pessoa, trabalhador ou serviço [16]. Concordamos com o pensamento dos autores, pois na UTI não há como se fazer uma dicotomia entre as tecnologias, pelo contrário, deve-se buscar uma articulação entre elas na busca de um cuidado integral. Ao se tratar de paciente crítico, as tecnologias duras, leve-duras, e leves tem a mesma importância, já que contribuem para uma assistência mais resolutiva, científica e humanizada.

É mister que o enfermeiro compreenda que a produção do cuidado deve ser um ato compartilhado e construído com o diálogo entre os pares, para que efetivamente seja prestado um cuidado humanizado e holístico. O diálogo horizontal, o processo decisório compartilhado e a co-responsabilização do cuidado devem ser valorizadas e implementadas dentro da UTI, para que todos os atores sociais envolvidos possam contribuir e se sentir importantes neste contexto.

\section{Os limites e as possibilidades para a supervisáo como ferramenta gerencial do enfermeiro para a produção do cuidado em UTI}

Apreendemos que na conformação da supervisão como ferramenta gerencial do enfermeiro para a produção do cuidado em UTI, as atividades desenvolvidas são permeadas por limites e possibilidades que direta ou indiretamente interferem no seu trabalho enquanto supervisor do serviço de terapia intensiva.

$\mathrm{Na}$ UTI, alguns limites aparecem no cotidiano da supervisão do enfermeiro. Entre os limites observados, está justamente a dificuldade encontrada em conciliar o alto grau de tecnologia e técnicas disponíveis, com um cuidado humanizado e integral ao paciente.

Essa tecnologia na UTI é evidenciada pelo uso e manuseio de materiais e equipamentos, que são utilizados para o alcance de necessidades que a natureza, por si só, não consegue alcançar ou que o ser humano está com dificuldade em fazer [18]. Apoiamos as autoras, quando afirmam que os respiradores, monitores e demais equipamentos podem prolongar e manter a vida do paciente, mas não necessariamente diminuem sua dor e solidão, que só podem ser aliviados com o cuidado humanizado.

Contudo, observa-se um exagero na importância que é dada as técnicas e aos equipamentos, muitas vezes deixando em segundo plano, a humanizaçáo, o acolhimento e a responsabilizaçáo. Existe a necessidade de equilibrar a relação entre a tecnologia e a humanização, pois em se tratando de UTI, ambas devem caminhar juntas para um cuidado adequado e digno.

A utilização dos equipamentos de ponta deve ser permeada pela escuta sensível, acolhimento, cuidado, olhar ao outro, superando o mito da UTI como local de morte. A integralidade perpassa por mudanças no cotidiano das instituiçóes de saúde, buscando-se a responsabilizaçáo no cuidado ao paciente, estabelecendo-se um vínculo e um cuidado que tenha como princípio as necessidades singulares dos sujeitos [17]. $\mathrm{Na}$ unidade de cuidado ao paciente crítico, o estresse é presença contínua no dia-a-dia de trabalho da equipe de saúde, já que a gravidade dos pacientes atendidos e as condiçóes do ambiente levam, na maioria dos casos, a sentimentos de ansiedade e até mesmo de medo, por parte dos profissionais.

Lucena e Crossetti analisam que a Enfermagem da UTI lida, diariamente, com urgências, sofri- 
mento e, não raras vezes, com a morte do paciente, situaçóes que acabam levando o profissional ao sofrimento e à frustração [18].

Apesar dos fatores limitantes presentes no exercício da supervisão do enfermeiro na UTI, existem possibilidades no cotidiano de trabalho.

A tomada de decisão compartilhada onde cada ator social participa e demonstra suas habilidades é essencial para uma supervisão social. Na UTI esse processo faz-se primordial à medida que o enfermeiro enquanto supervisor assume responsabilidades, delega funçóes e utiliza-se de meios para avaliar os resultados obtidos pelos membros da equipe. O enfermeiro deverá aplicar a criatividade para a tomada de decisóes, adequando recursos materiais e humanos com a finalidade da execução de uma assistência planejada e com qualidade, estimulando a participação e envolvimento da equipe.

O trabalho em equipe representa mais uma possibilidade durante a supervisão do enfermeiro na UTI. A supervisão deve valorizar a participação dos diversos atores sociais envolvidos, estimulando a criatividade e permitindo que todos se sintam atuantes na construção do cuidado, criando vínculos importantes entre a equipe.

Correia e Servo afirmam que "o supervisor deve colocar-se como um elemento pertencente ao grupo e náo superior a este, posicionando-se a favor dos interesses coletivos, de forma a possibilitar uma melhoria da assistência prestada" [12].

É função do enfermeiro estar atento a todos os componentes de sua equipe, na qual uns cuidam dos outros e todos cuidam do paciente, desenvolvendo o espírito de coleguismo, de motivação, de respeito às individualidades, aos valores, às crenças e à subjetividade que é inerente a cada um [15].

A capacitaçáo dos profissionais, o treinamento e a orientação são compreendidos como fator decisivo no processo de supervisão. A capacitação/ orientaçáo deve ser entendida como possibilidade para o exercício da supervisáo.

Um dos objetivos da supervisão é manter a educação permanente dos trabalhadores de saúde através da avaliação constante do serviço realizado por estes, buscando identificar as necessidades de orientaçáa e treinamento, no intuito de prevenir situaçôes problemáticas [12]. As autoras afirmam que a supervisão adquire relevância no tocante à influência que exerce sobre o desempenho dos funcionários, possibilitando que as atividades nas instituiçóes sejam realizadas de forma satisfatória.
Compartilhar conhecimentos e estabelecer uma relação de troca e crescimento mútuo é indispensável para a melhoria na produção do cuidado e nas relaçóes interpessoais dentro do ambiente de produção do cuidado.

$\mathrm{Na}$ enfermagem atual faz-se necessário uma liderança supervisora mais compartilhada e democrática, onde os líderes acreditem no valor dos indivíduos e na colaboração de cada um na construção do todo. $\mathrm{O}$ verdadeiro líder deve incentivar a participação dos funcionários, utilizando-se de uma liderança de apoio, compartilhando com os membros da equipe a tomada de decisão. Existe a necessidade do enfermeiro em liderar orientando, vislumbrando o crescimento do ser e consequentemente da equipe.

\section{Conclusão}

A supervisão em uma unidade de cuidados críticos vislumbra integrar o cuidado de pacientes graves e de risco a um ambiente em harmonia e segurança, valorizando a subjetividade, as emoções, os medos e as perspectivas do paciente e da equipe, buscando a manutenção da vida e a integralidade da assistência.

Através deste estudo verificou-se que a supervisão atual perpassa pelos sentimentos que estão tão aflorados na UTI, seja em relação aos pacientes, como também a todos os membros da equipe, além do aprimoramento dos trabalhadores, estimulando o exercício de suas habilidades e competências individuais. Entender sua função de articulador e de líder dentro da equipe permitirá ao enfermeiro compreender a supervisão, bem como as nuances nela envolvidas.

Os limites apreendidos para o exercício da supervisão foram: o estresse que acomete a equipe e que termina influenciando na produção do cuidado, bem como a dificuldade encontrada em conciliar o alto grau de tecnologia com um cuidado humanizado e integral ao paciente. Por outro lado, podemos citar como possibilidades o treinamento e capacitação, liderança humanizada, as relaçóes interpessoais e o trabalho em equipe.

Tem-se a certeza que a realizaçáo deste estudo não esgotou a temática em discussão, porém mantém a esperança de se ter conseguido penetrar no mundo do enfermeiro intensivista, compreendendo o significado da supervisão como importante ferramenta para a produçáo do cuidado. É necessário que 
novos trabalhos sejam feitos para explorar o conhecimento desta área, e que muito precisa ainda ser pesquisado, tendo em vista contribuir para elucidar a realidade da supervisão do enfermeiro na UTI, assim como estimular reflexóes acerca da temática.

\section{Referências}

1. Pinho LB, Santos SMA. Dialética do cuidado humanizado na UTI: contradiçôes entreo discurso e a prática profissional do enfermeiro. Rev Esc Enferm USP 2008;42(1):72-66.

2. Nascimento KC, Erdmann AL. Cuidado transpessoal de enfermagem a seres humanos em unidade crítica. Rev Enferm UERJ 2006;14(3):341-33.

3. Costa SC, Figueiredo MRB, Schaurich D. Humanização em Unidade de Terapia Intensiva Adulto (UTI): compreensóes da equipe de enfermagem. Interface Comunic Saúde, Educ 2009;13(1):571-80.

4. Martines WRV, Machado AL. Produção de cuidado e subjetividade. Rev Bras Enferm 2010;63(2):328-33.

5. Franco TB. Produção do cuidado e produção pedagógica: integração de cenários do sistema de saúde no Brasil. Interface - Comunic., Saúde, Educ 2007;11(23):42738.

6. Almeida AHV, Servo MLS. A supervisão realizada pelo enfermeiro no SAMU de Feira de Santana-BA. Diálogos \& Ciência 2011;26.

7. Greco RM. Ensinando a administração em enfermagem através da educação em saúde. Rev Bras Enferm 2004;57(4):507-4.
8. Servo MLS. Planejamento estratégico situacional: Uma possibilidade para a sistematização da supervisáo em enfermagem. Rev Gaúch Enferm 2000;2:59-39.

9. Servo MLS, Correia VS. A supervisão sob a ótica dos auxiliares de enfermagem. Diálogos \& Ciência 2005;6:14-1.

10. Carvalho JFS, Chaves LDP. Supervisão de Enfermagem no contexto hospitalar: uma revisão integrativa. Rev Eletr Enferm 2011;13:520-8.

11. Bardin L. Análise de conteúdo. Lisboa. Portugal: Ediçôes; 1977 . p.70.

12. Correia VS, Servo MLS. Supervisão da enfermeira em Unidades Básicas de Saúde. Rev Bras Enferm 2006;59(4):531-27.

13. Liberali J, Dall'Agnol CM. Supervisão de enfermagem: um instrumento de gestáo. Rev Gaúch Enferm 2008;29(2):276-82.

14. Kurcgant P, Ciampone MHT, Melleiro MM. O planejamento nas organizaçóes de saúde: análise da visão sistêmica. Rev Gaúch Enferm 2006;27:351-5.

15. Martins JT, Robazzi MLCC, Marzial EMHP. Significados do gerenciamento de unidade de terapia intensiva para o enfermeiro. Rev Gaúch Enferm 2009;30(1):113-9.

16. Marques GQ, Lima MADS. As tecnologias leves como orientadoras dos processos de trabalho em serviços de saúde. Rev Gaúch Enferm 2004;25(1):25-7.

17. Gelbcke FL, Souza LA, Sasso GM. Liderança em ambientes de cuidados críticos: reflexôes e desafios à enfermagem brasileira. Rev Bras Enferm 2009 62(1):139-6.

18. Lucena AF, Crossetti MGO. Significado do cuidar na unidade de terapia intensiva. Rev Gauch Enferm 2004;25(2):243-56. 